\title{
A propósito de un cáncer de vejiga
}

\section{neuroendocrino mixto}

\author{
Navarro Medina, P.*; Artiles Hernández, J.L.*; Camacho García, C.**; Blanco Diez, A.*; Armas Molina, J.*; Chesa Ponce, N. ${ }^{*}$ \\ * Servicio de Urología. Hospital Universitario Insular de Gran Canaria. \\ ** Servicio de Anatomía Patológica. Hospital Universitario Insular de Gran Canaria.
}

\section{Resumen}

\section{Objetivo}

Presentación de un caso clínico de carcinoma neuroendocrino de celularidad mixta.

\section{Método y resultados}

Presentamos el caso de un varón de 71 años que consultó por un episodio de hematuria macroscópica. Se realizó cistectomía parcial, ya que el pacientes por su patología respiratoria de base no podía ser sometido a cistectomía radical. Siendo el informe anatomo-patológico definitivo de carcinoma neuroendocrino mixto de alto grado de malignidad, carcinoma indiferenciado de célula pequeña y carcinoma neuroendocrino de célula grande infiltrando la capa muscular superficial y profunda. Hasta la actualidad no evidencia recidiva local ni metástasis a distancia del proceso tumoral.

\section{Conclusión}

El paciente que nos ocupa, la celularidad mixta de carcinoma neuroendocrino de célula pequeña y carcinoma neuroendocrino de células grandes sólo se ha descrito, según nuestro conocimiento, hasta el momento actual un caso ${ }^{1}$. La cistectomía parcial y el tratamiento quimioterapico neoadyuvante, han mantenido libre de enfermedad 5 años después, a este enfermo.

\section{Introducción}

El cáncer de vejiga neuroendocrino es una patología poco frecuente. Esta variedad de tumores son más frecuentes en el pulmón y tracto gastrointestinal. Dentro de los tumores neuroendocrinos de vejiga, el subtipo más frecuente es el de células pequeñas descritos hasta el momento, más de cien casos, menos común en estos tumores son el de células grandes, encontrando hasta la actualidad cuatro casos descritos en la literatura científica.Y en el paciente que nos ocupa, la celularidad mixta de carcinoma neuroendocrino de célula pequeña y carcinoma neuroendocrino de células grandes sólo se ha descrito, según nuestro conocimiento, hasta el momento actual un caso ${ }^{1}$.

\section{Caso clínico}

Presentamos el caso de un varón de 71 años con antecedentes personales de hipertensión arterial, hernia de hiato, hipoacusia, fibrilación auricular paroxística y enfermedad pulmonar obstructiva crónica. Exfumador. Agricultor con exposiciones frecuentes a pesticidas. En tratamiento con -bloqueantes por hiperplasia benigna de próstata.

En octubre del 2002 consultó por un episodio de hematuria macroscópica con coágulos, sin otra sintomatología acompañante, observando en cistoscopia una neoformación pediculada sólida, de color blanquecino y 2.7 centímetros de diámetro mayor, en cara anterior de vejiga. Un mes después se realizó resección transuretral de vejiga cuyo informe anatomopatológico se informó como: carcinoma urotelial grado 3 con infiltración de la capa muscular (pT2G3), sin imágenes de invasión vascular ni infiltración perineural. Los estudios posteriores de extensión (TAC abdominopélvico y tórax) resultaron negativos.

En diciembre de 2002 se realizó cistectomía parcial, ya que el paciente por su patología respiratoria de base no podía ser sometido a cistectomía radical. El postoperatorio concluyó sin incidencias, a destacar.

En el informe anatomopatológico destacaba la infiltración de las capas musculares de la vecindad del borde quirúrgico lateral. Histológicamente correspondía a una neoplasia indiferenciada dispuesta en nidos sólidos en cuyo seno se identificaban frecuentes rosetas, abundantes figuras de mitosis y focos de 


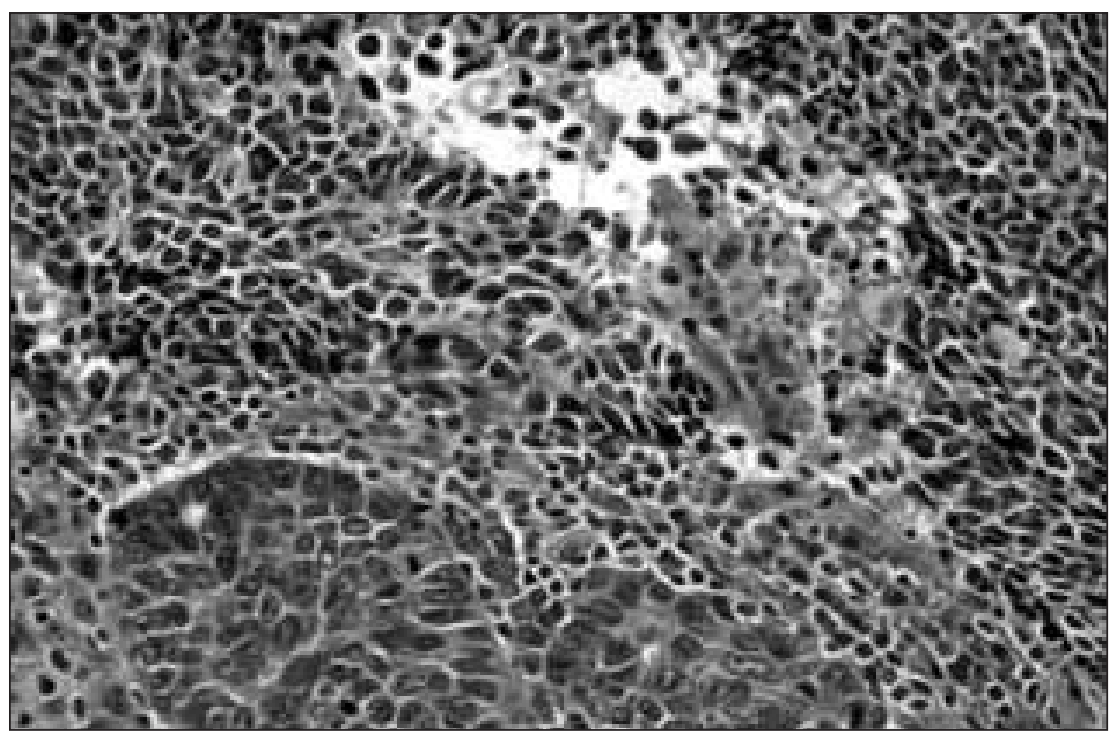

Figura 1

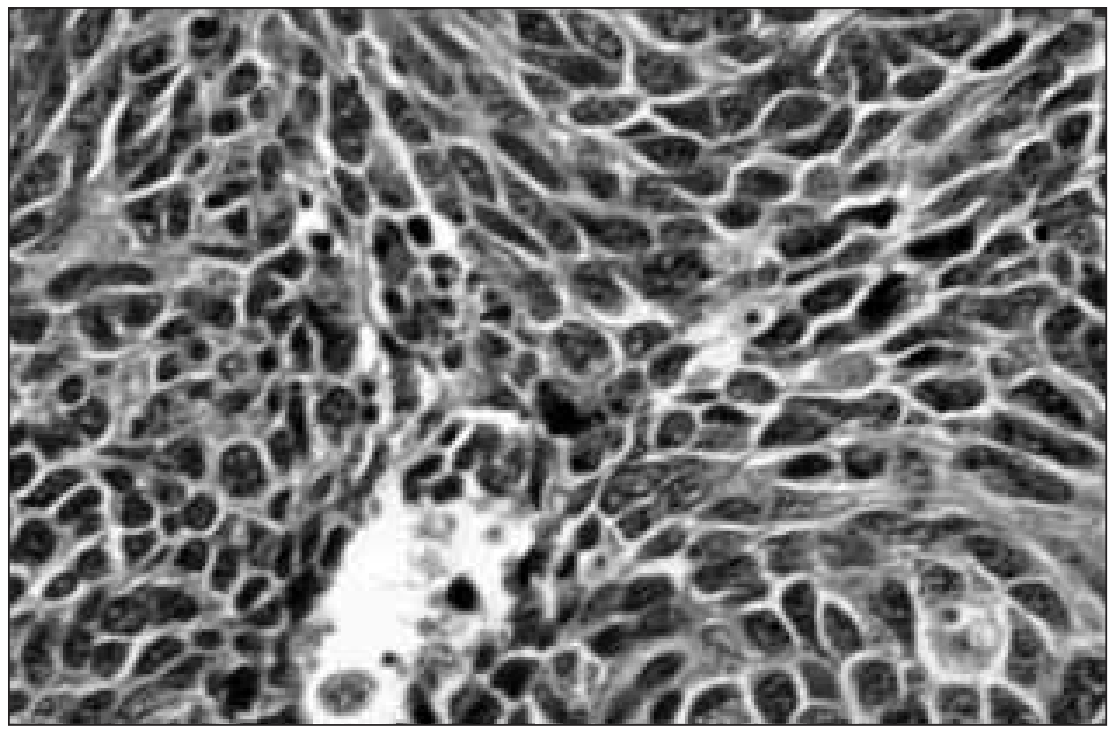

Figura 2

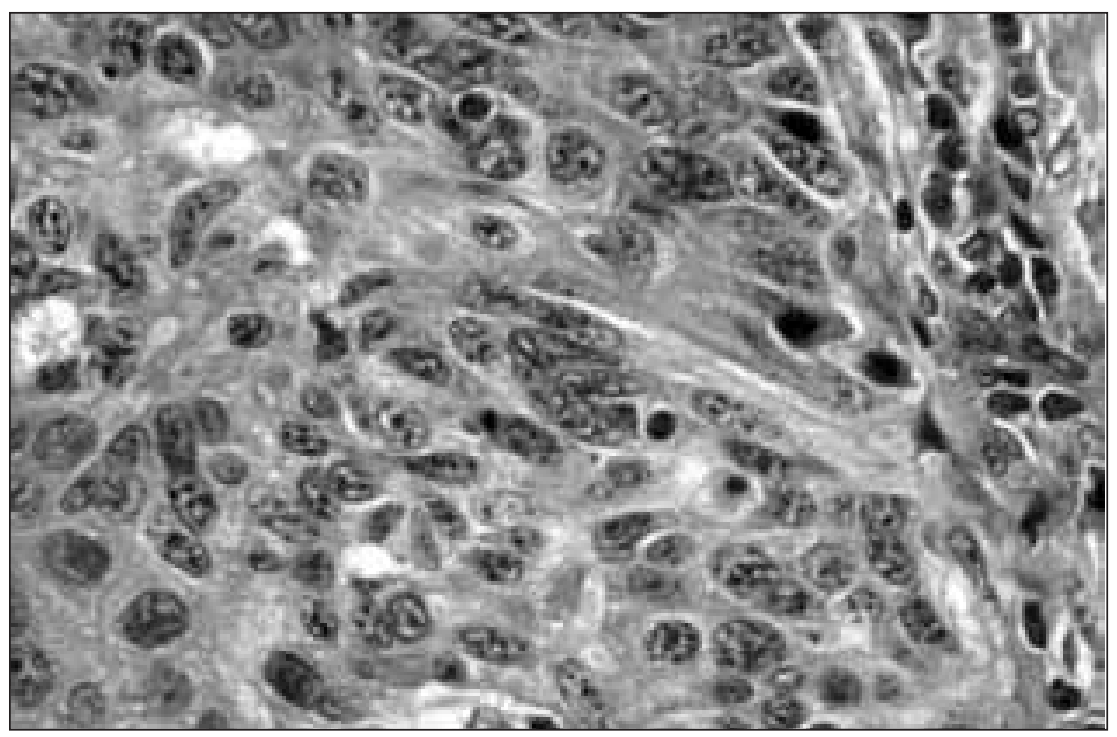

Figura 3 necrosis. Incluyendo dos poblaciones celulares entremezcladas entre si (figura 1) una de las cuales es de tamaño intermedio con escaso citoplasma y núcleos regulares de cromatina granular con moldamiento nuclear (figura 2). Junto a estas se identificaban áreas donde las células aunque presentan cromatina granular son de tamaño intermedio-grande incluyendo moderado citoplasma (figura 3). Inmunohistoquímicamente las células presentaban positividad intensa y difusa para citoqueratina de amplio espectro y marcadores neuroendocrinos (sinaptofisina y cromogranina).

La diferenciación neuroendocrina se confirmó inmunohistoquímicamente y se informó como: células tumorales con positividad intensa para citoqueratina, enolasa neuronal específica y positividad ligera y difusa para sinaptofisina, la cromogranina era negativa. Siendo el informe definitivo de: Carcinoma neuroendocrino mixto de alto grado de malignidad, carcinoma indiferenciado de célula pequeña y carcinoma neuroendocrino de célula grande infiltrando la capa muscular superficial y profunda, con afectación perineural..

Recibió entre diciembre de 2003 y marzo 2004 cuatro ciclos de quimioterapia adyuvante con Paclitaxel-Carbol, con buena tolerancia.

Hasta la actualidad, los controles por cistoscopia y citología urinaria que se realizan semetralmente, así como tomografia axial computerizada abdomino-pélvica no evidencian recidiva local ni metástasis a distancia del proceso tumoral.

\section{Discusión}

El primer caso descrito de un carcinoma neuroendocrino primario de vejiga fue en el año 1986 , por Abenzoa et $\mathrm{al}^{2}$. Se han publicado más de un centenar de tumores neuroendocrinos de células pequeñas primarios de vejiga, diversos casos de tumores de células pequeñas y adenocarcimas. Pero sólo hemos encontrado un caso de tumor primario de vejiga con celularidad 
neuroendocrino mixta, de células pequeñas y grandes ${ }^{1,3}$.

La etiología del tumor primario de vejiga neuroendocrino es hasta el momento, muy discutida. Aunque la hipótesis con mayor número de adeptos, apunta a un carcinoma urotelial de alto grado.

Factores de riesgo implicados son por el número reducido de casos conocidos una incógnita. Aunque si extrapolamos los aparecidos en los tumores neuroendocrinos de vejiga parecen incluir el varón en torno a la séptima década de la vida.

La presentación clínica no parece diferir mucho de los clásicos tumores del urotelio, con hematuria macroscópica.

El tratamiento de elección en estos tumores probablemente sea la cistectomía radical, aunque en el caso que aportamos la cistectomía parcial se ha acompañado de un periodo libre de enfermedad de cinco años, la quimioterapia adyuvante parece tener un papel importante, aunque aún por definir. El papel de la radioterapia coadyuvante aún no ha sido definido. Los carcinomas neuroendocrinos de células grandes de la vejiga parecen sensibles a la quimioterapia y es nuestro caso concreto.
El pronóstico, en general de los carcinomas neuroendocrinos de vejiga, parece ser fatal ${ }^{4,5}$, fundamentalmente por el estadío avanzado en el que son diagnosticados los pacientes, hasta el momento descritos en la literatura médica. Especialmente para los carcinomas neuroendocrinos de célula grande, pronóstico que viene marcado por su precoz infiltración en profundidad. Tanto las complicaciones del crecimiento local como las metástasis a distancia marcan el mal pronóstico de estos tumores ${ }^{6}$. El diagnóstico diferencial temprano se hace especialmente importante, de cara al tratamiento específico.

\section{BIBLIOGRAFÍA}

1. Quek ML, Nichols PW, Yamzon J, Daneshmand S, Miranda G, Cai J, Groshen S, Stein JP, Skinner DG. Radical cystectomy for primary neuroendocrine tumors of the bladder: the university of southern california experience. J Urol. 2005 Jul;174(1):93-6.

2. Abenoza P, Manivel C, Sibley R. Adenocarcinoma with neuroendocrine differentiation of the urinary bladder. Arch Pathol Lab Med 1986;110:1062-1066.

3. Ali S, Reuter V, Zakowski M. Small cell neuroendocrine carcinoma of the urinary bladder: a clinicopathologic study with emphasis on cytologic features. Cancer 1997; 79: 356-361444 Lee KH, Ryu SB, Lee MC, Park CS, Juhng SW, Choi C. Primary large cell neuroendocrine carcinoma of the urinary bladder. Pathol Int. 2006 Nov;56 (11): 688-93.

4. Li Y, Outman JE, Mathur SC. Carcinosarcoma with a large cell neuroendocrine epithelial component: first report of an unusual biphasic tumour of the urinary bladder. J Clin Pathol. 2004 Mar; 57(3):318-20.

5. Hailemariam S, Gaspert A, Komminoth P, Tamboli P, Amin M. Primary, pure, large-cell neuroendocrine carcinoma of the urinary bladder. Mod Pathol. 1998 Oct;11(10):1016-20.

6. Evans AJ, Al-Maghrabi J, Tsihlias J, Lajoie G, Sweet JM, Chapman WB. Primary large cell neuroendocrine carcinoma of the urinary bladder. Arch Pathol Lab Med. 2002 Oct; 126(10):1229-32. 